\section{The environment and the eye}

\begin{abstract}
The use of the 'environment' has become extended to include population changes, the 'domestic' environment, and cultural factors, in addition to physical influences such as global warming and ultraviolet radiation (UVR). The likely effects of each of these classes of agents on the eye and rates of blindness are illustrated by reference mainly to cataract and trachoma - two of the commonest causes of the world blindness.

Trachoma infection and its blinding consequences could be eventually eliminated by environmental measures and changes in behaviour. While the threat of increased incidence of blindness from cataract due to ozone depletion and greater solar UVR has receded, global warming may become a factor in the early onset and rapid progression of cataract. Although we continue to need research into the physical and biological causes of cataract, elimination of world blindness will only be achieved when we understand the conceptual and cultural environments which are inhibiting the acceptance of cataract surgery. Eye (2004) 18, 1235-1250. doi:10.1038/sj.eye.6701369 Published online 26 March 2004
\end{abstract}

Keywords: eye disease; environment; cataract; trachoma; climatic droplet keratopathy

\section{Definitions, Classification, and Plan}

What is included in the term 'environment'?

'The environment is anything that is not me!' is a definition often attributed to Albert Einstein. In relation to issues of health, the environment can be thought of as everything affecting the causation or outcome of disease which is not genetic. It may be difficult to isolate these influences. Very few conditions are either entirely 'genetic' or entirely 'environmental'. Genes do not act except within environments, and environments do not act on anything other than organisms, cells, or molecules - that is, the products of genes. Sorting out these complex interactions is the province of genetic epidemiology.
GJ Johnson

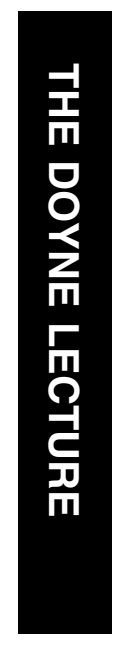

Historically, study of the environment arose with inorganic and organic influences on plants and forestry, such as climate and climate change, soil and erosion, and infectious agents. Gradually, the use of the term has been extended to include the bio-domestic environment, the political and policy environment, and even the business environment.

When we consider the possible environmental influences on health, the different factors can be arbitrarily classified as below. At the same time, we realize that they do not exist as discrete entities, but interact in complex webs, and also that the environment is always changing:

1. Population (demography): Any consideration of the effect of environments on health must include life expectancy and the size and trends in human population. Humans modify the environment through their actions. Population size may be critical to survival in areas of marginal subsistence.

2. 'Abiotic' (physical) environment: This includes climate (temperature, including trends and variability; precipitation, floods, humidity; extreme weather; wind; soil erosion), ultraviolet radiation, pollution (volcanic activity; air pollution, chemicals, particles; acid rain; chemicals in water sources), and electromagnetic fields.

3. 'Biotic' environment: infectious agents and vectors. Forestry, agriculture, fisheries and biodiversity loss may affect health indirectly.

4. 'Domestic' environment: This term has been adopted to mean a person's immediate hygienic and household environment, which usually involves some human choice - the environments we make for ourselves. Factors include washing habits, water supply, sanitation, diet and lifestyle (smoking, alcohol use, exercise). Work habits, for example close-work, may be important in relation to the incidence of refractive errors.

5. Politico-cultural environments: The conceptual or cultural background of a population may
International Centre for Eye Health London School of Hygiene and Tropical Medicine \& Department of Epidemiology and International Eye Health Institute of Ophthalmology, UCL UK

Correspondence:

GJ Johnson, MA MD BChir FRCS(C) FRCOphth DCEH

17 Lucerne Road Summertown Oxford OX2 7QB, UK

Tel: $+44(0) 1865556513$ Fax: + 44 (0)1865 310941

E-mail: g.j.johnson@

btopenworld.com

Published online: 26 March 2004

This paper was previously presented as the Doyne Lecture at the Oxford Ophthalmological Congress, Tuesday, 8th July 2003 
be a major influence on both the aetiology and outcome of disease. Elements include philosophical and religious outlook; cultural practices; equity of access to health services; priority given to health in national policy; and the culture of medical practice.

The major political influences are war, terrorism, and security. For example, after the 1991 Iraq war, children began to present with keratomalacia due to vitamin $\mathrm{A}$ deficiency.

6. Socio-economic environment: Many aspects of the economic and social situation affect disease, such as poverty, inequality in income and assets, the 'business environment', macro-economic policy, financial instability, and corruption.

7. Legal environment: The legal framework within which medicine is practised can influence the doctors' choices of intervention.

8. The 'built environment': is a term sometimes used. This includes the urban environment; design and quality of housing, and design of health facilities.

\section{Plan}

Many of these environmental influences impinge on the eye in one way or another - either in the aetiology of eye disease or in the effectiveness of treatment. This is a large menu, and this paper will have to be selective. Examples of five major environmental influences will be given:

- life expectancy and population;

- global warming;

- UV radiation and the ozone layer;

- 'domestic' environment;

- cultural environment.

Their possible effects will be illustrated by two of the three commonest causes of blindness in the modern world, cataract (50\% of global blindness) and trachoma (approximately 9\%), and, in addition, reference is made to less common external eye conditions. Glaucoma is almost certainly now the second cause of worldwide blindness (approximately 14.5\%). The heritability of both primary open-angle glaucoma (POAG) and primary angle closure is thought to be around $80 \%$. Nevertheless, there are important environmental risk factors to be confirmed. Progress has been made in identifying some of the many genes likely to predispose to POAG. This is an area of active investigation, and much work needs to be done to elucidate their possible interaction with environmental factors. Nevertheless, it may be some years before this interaction can be described. Likewise, the genetic basis for age-related macular degeneration (ARMD) and the interaction with known risk factors is under intense investigation. Glaucoma and ARMD will not be discussed further here.

Why do we study the influence of the environment on eye disease? This is not only for its intrinsic scientific interest, but also because it may show us how some preventive measures can be introduced or control measures improved.

\section{Life expectancy and population}

Throughout the world, our length of life and our health have improved dramatically over the past 200 years. ${ }^{1}$ In early human history, as illustrated by stone-age skeletons from North Africa, life expectancy was 21 years. The average citizen of Imperial Rome lived only 22 years. During the Middle Ages in England, life expectancy for male land holders was around 35 years, declining precipitously during the Black Death. Around 1540, parish records became available for both men and women (Figure 1). From the early 19th century, life expectancy soared, probably as a result of improved access to food, clean water, and sanitation, so that it is now around 78 years. This is a universal trend. In the developing countries, it started later and progressed more rapidly, from 41 years in 1950 to 65 years in $1998 .^{2}$ The region that is lagging at present is sub-Saharan Africa, largely due to AIDS. Even here, it is projected to catch up by 2050 .

The historical sequence is that first the death rate falls, and this is followed 50-100 years later by a fall in the birth rate (Figure 2). This so-called 'demographic transition' occurred first in the countries of northern Europe and progressed over approximately 200 years. It is now being compressed into 100 years or less in many developing countries. The number of births per woman in developing countries has fallen from six in the early 1950 s to three today. The UN estimates that it will go to 2.1 by $2045-50 .^{2}$

Throughout the world, the fall in the death rate, before the drop in birth rate, has lead to a dramatic increase in population numbers. This massive growth rate began around 1950, and will probably tail off around 2050 (Figure 3). The absolute growth of the world's population peaked around 1990, when 87 million were added. In 1999, we passed the 6 billion mark. The present medium prediction is that the world population will pass 9.3 billion in $2050^{2}$ and stabilize just short of 11 billion in 2200. The decline in birth rate is, however, not uniform across all regions. The population of sub-Saharan Africa as a proportion of the total world population will increase from $9 \%$ in 1950 to $22 \%$ in $2050,{ }^{1}$ which will have serious implications for training of enough ophthalmologists and other health staff. 


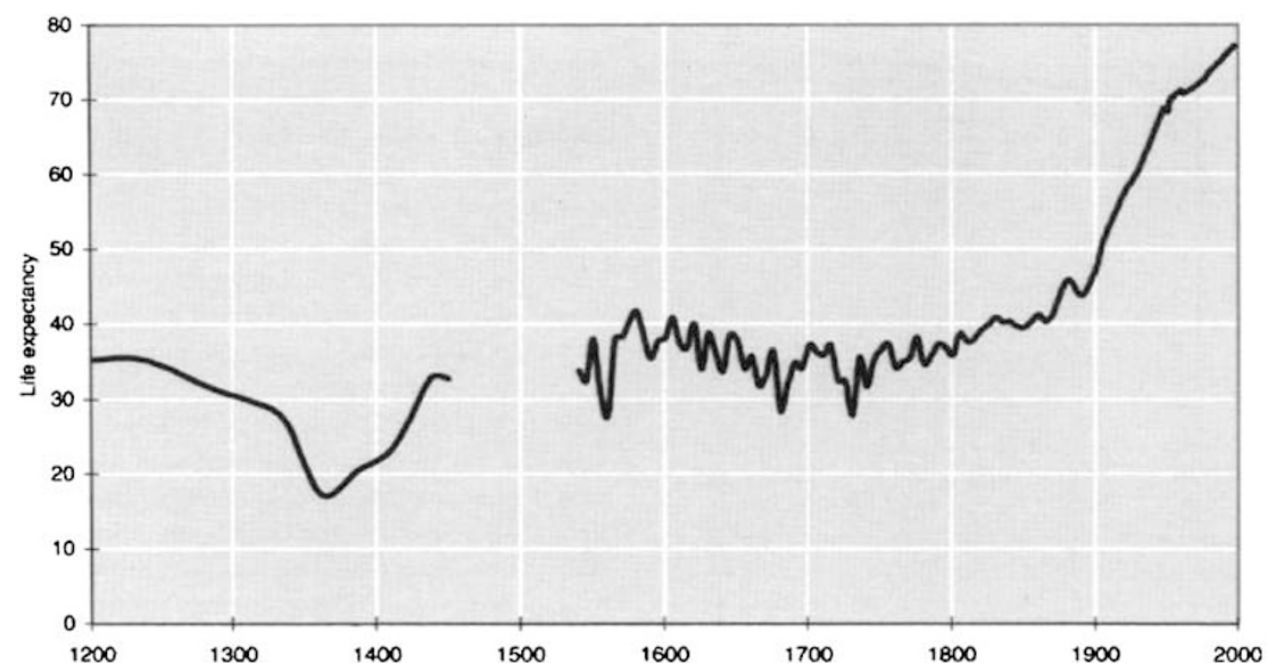

Figure 1 Life expectancy over 800 years in England and Wales.

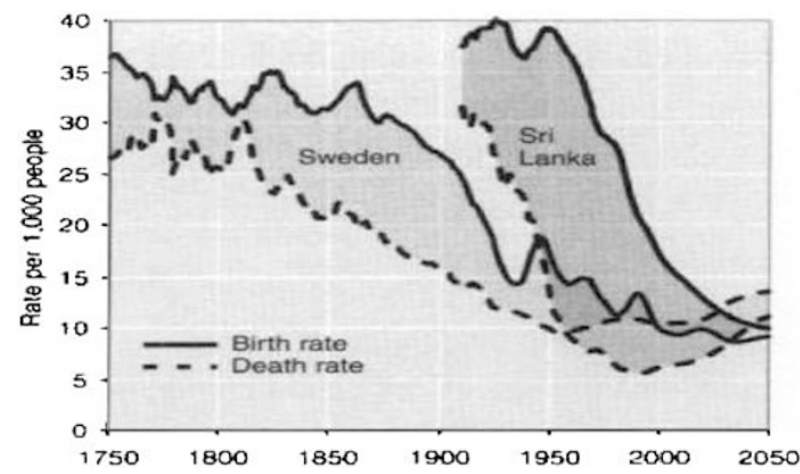

Figure 2 The demographic transition in Sweden and Sri Lanka.

Most of the chronic eye diseases we deal with ARMD, cataract, glaucoma - are age-related. The increase in life expectancy means that the prevalence of each is increasing steadily, and possibly exponentially.

This is especially true of cataract. However, the association is more complicated than a direct relationship with age in years. Two of the unsolved questions are why does visually-disabling cataract come on so much earlier in developing countries, particularly in India, and why is it so much more prevalent in developing countries than in industrialized countries?

\section{Causation of cataract in relation to age}

There is a large literature on the risk factors for agerelated cataract. ${ }^{3}$ Many studies, in India but also elsewhere, have found consistent associations between cataract and some general socio-economic indicators reflecting aspects of the environment. These include low socio-economic status, low educational level, rural rather than urban residence, and low height, weight, and body-

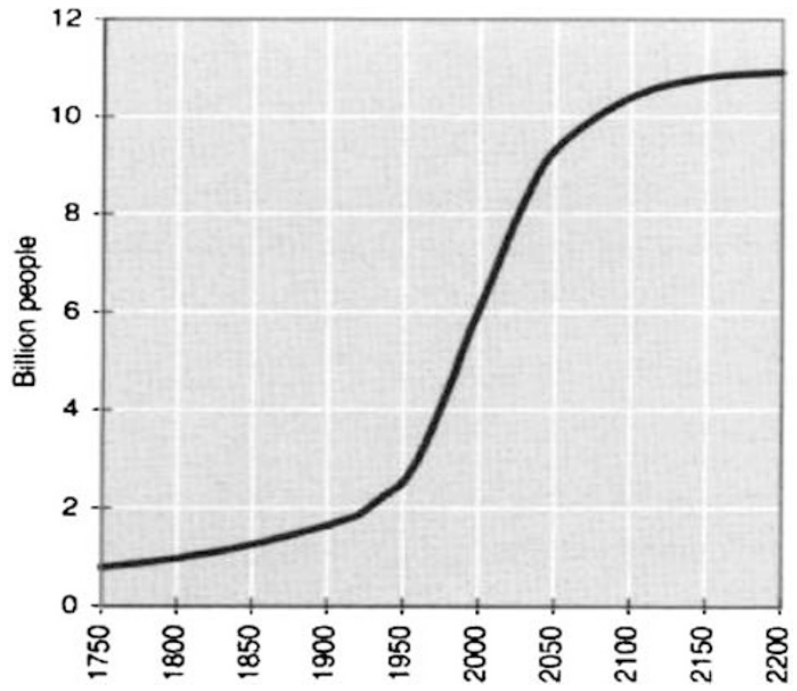

Figure 3 World population 1750-2200.

mass index. Average height is regarded in public health as an indicator of the health of a population; ${ }^{1}$ it is closely linked to health and adequate nutrition from embryo to adulthood. Tall people have a relatively lower mortality (at least up to $192 \mathrm{~cm}$ or $6 \mathrm{ft} 4 \mathrm{in}$ ). Western European populations have all got taller over the past 200 years. When you visit an eye camp in India, one of the things that strikes you - besides the numbers and the young average age - is how short the majority of the patients are. What are these general risk factors trying to tell us about the aetiology of cataract?

A series of studies of cataract have been conducted by Minassian, Mehra, and Reidy in the city of Raipur and surrounding villages in Madhya Pradesh in central India. After systematic baseline examinations, it was possible to follow cohorts of people in these villages for 4 years or 
more. It was in this setting that the doubling of the risk of death (death ratio 2.2 after 4 years) in nondiabetics with central lens opacities was first demonstrated. ${ }^{4}$ This applied equally to those with adequate vision, better than $6 / 18$, as to those with impaired vision. This association of cataract with mortality has since been found in other countries. ${ }^{5,6}$ Although, at present, we do not know what the specific cellular or biochemical mechanisms might be, are lens opacities offering us a 'window' into the processes leading to accelerated mortality? In other words, are some of the same environmental factors causing both early onset of cataracts and early death?

I wish to hypothesize here that the average age of onset of cataract in a population may be correlated with the average life expectancy. In the same way that Gilbert has been able to predict the prevalence of childhood blindness in a population from the under- 5 mortality rate, ${ }^{7}$ it is suggested that we shall find, at the other end of life, that we may be able to predict the age of onset of visual impairment due to cataract from the life expectancy.

If true, the situation regarding the number of cataract operations to be performed in India may not be quite as bad as it appeared at first sight. There will still be a big rise in total cataract numbers, but they will occur at a later age in years. As the life expectancy in India and similar developing countries increases with

environmental improvements, there will not be the same number of cataracts requiring operations at 35 or 45 years of age.

\section{Global warming}

Global warming has been the overriding physical environmental concern for the past decade. The so-called 'greenhouse gases' in the atmosphere trap some of the heat emitted from the earth's surface, which comes from solar irradiation. This 'blanket' wrapped around the globe is essential to life, as we know it. Without it, too much heat would be dissipated into space and the average temperature of the earth would be $33^{\circ} \mathrm{C}$ lower.

Several types of gases can reflect or trap heat, including carbon dioxide $\left(\mathrm{CO}_{2}\right)$, methane, nitrous oxide, water vapour, halocarbons, and ozone. Particulate material such as sulphur dioxide and dust reflects solar irradiation, while other particles such as black carbon retain heat.

Knowing the patterns of climate change over the past several centuries is essential to assessing the possible human impact on the postindustrial climate. Direct temperature measurements have only been collected systematically and from enough locations around the globe for the past 100 years or so. ${ }^{1,8}$ These instrument readings can be used to calibrate various proxy-

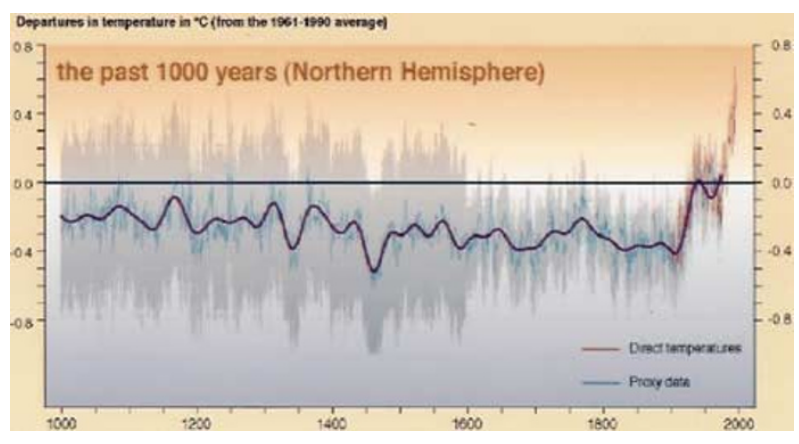

Figure 4 Temperature variations in the Northern Hemisphere.

indicators, such as tree rings, study of ice cores drilled out of polar regions, and corals (growth rings and trace elements), in order to study the temperature further back in time. ${ }^{9}$ Different data series constructed in this way for the Northern hemisphere point to a gradual decline in temperature over the past millenium until around 1900 (Figure 4). From 1910, there has been an abrupt increase of around $0.4-0.8^{\circ} \mathrm{C}$. The past decade has been warmer than anything for 1000 years.

The problem is that there have been substantial natural temperature swings every 1500 years of so over the past 140000 years, some indicators even showing a change of $5-8^{\circ} \mathrm{C}$ over 1500 years. There are also shorter swings due to variations in solar radiation and volcanic dust. Is the recently observed global temperature increase part of these cyclic changes or is it a new phenomenon?

There is now general agreement that the change observed since approximately 1900 is too abrupt to be part of the normal swings, and that it is mostly anthropogenic, that is, induced by the activities of mankind. Human activity is thought to have increased the quantity of the extra heat-trapping gases which are responsible for the so-called 'greenhouse effect', particularly carbon dioxide which makes up $60 \%$ of this effect. About $80 \%$ of the extra $\mathrm{CO}_{2}$ comes from the combustion of oil, coal, and gas, whereas the other $20 \%$ comes from deforestation and other changes in land use in the tropics.

Many extremely complex computer models, known as Atmosphere-Ocean General Circulation Models or GCMs, which differ between themselves as well as with different scenarios, are being used to try to predict how much the temperature will increase in the future.

The three most difficult problems for the climate simulations are modelling the cooling effect of particles, fitting in the water vapour, and how to handle the influence of clouds. Using the best available models, the predictions for the temperature rise to 2100 are regularly updated by the Intergovernmental Panel on Climate Change (IPCC). The current best estimates are between 1.4 and $5.8^{\circ} \mathrm{C}$ by $2100 .{ }^{8}$ Obviously, what you think may 
happen will depend on which end of this range you take. The mid-range is $3.6^{\circ} \mathrm{C}$. Within this overall range, regional variations are expected, some areas showing greater degrees of global warming, other areas less. Land surfaces will warm more than the oceans.

There is already some evidence of extension of the geographical range of some plant and animal species, and of certain infectious diseases. ${ }^{10,11}$ What effects might global warming have on eye disease?

\section{Fungal keratitis}

Fungal keratitis thrives in hot climates. As a proportion of all cases of suppurative keratitis, those due to fungi increase inversely with latitude. ${ }^{12}$ Whereas it may be $2-$ $3 \%$ of suppurative keratitis in London, it reaches over $50 \%$ of the total suppurative corneal infections close to the equator in southern Ghana. With an average rise of ambient temperature of $3^{\circ} \mathrm{C}$, it is possible that the incidence and geographical range of fungal keratitis may increase. Fusarium species are plant pathogens, spread in moisture. These infections are likely to be favoured in localities where the climate becomes hotter and wetter. The spores of Aspergillus, on the other hand, are resistant to dessication, and their air-borne spread would be favoured by a hotter and drier environment. ${ }^{13}$

\section{Trachoma}

As will be seen below, infection by trachoma is classically favoured by a hot, dry, dusty environment. Its range could theoretically extend with global warming. However, in this disease, changes in individual behaviour are of overriding importance, and the success of current control measures would make it very difficult to detect any such effect.

\section{Temperature rise and cataract}

Could increasing global temperature have any influence on the incidence and age of onset of cataract?

The series of studies conducted by Minassian and colleagues in Raipur, to which reference has already been made, included three case-control studies, of different design, which consistently identified dehydrational crises as a major risk factor for cataract, in this geographical setting. ${ }^{14,15}$ This usually took the form of severe, life-threatening diarrhoea - a cholera-like illness. There was a marked dose-dependent relationship of pre-senile cataract with remembered episodes of severe diarrhoea, in a consistent and dose-dependent manner, which strongly suggested a causal association. ${ }^{14}$ There was also a compounding effect with heatstroke. A single remembered episode of heatstroke increased the relative risk of cataract to 1.75; an episode of severe diarrhoea increased it to 6 . If the subjects had experienced both heatstroke and severe diarrhoea, they had a 15 times greater risk of cataract relative to someone exposed to neither.

The first study suggested that approximately $40 \%$ of the cataracts in the first population could be attributed to these causes (the Summary Population Attributable Risk, PAR\%), and 38\% in the second study. The attributable risk, or attributable fraction, is the maximum proportion of cataract in a population, which can be attributed to a characteristic or aetiologic factor. Another way of thinking about attributable risk is as the proportional decrease in the incidence of cortical cataract if the entire population were no longer exposed to the factor.

A third study (unpublished) was conducted in the same area of India by a third methodology, again demonstrating the association. This therefore seems to be a real finding in this geographical area. Harding has suggested the plausible biochemical mechanisms by which dehydrational crises might affect the conformation of lens proteins. ${ }^{16}$

The association of cataract with severe diarrhoea was not confirmed in two other studies, one in Madurai, Tamil Nadu, ${ }^{17}$ the other in Dhaka, Bangladesh. ${ }^{18}$ The methodologies of these studies were not comparable to those by Minassian and Mehra. It may also be the case that dehydrational crises and heatstroke are risk factors for cataract which apply particularly in central India. Weather maps show that Raipur is included in the hottest part of India in the months of April and May, both the 20 years average temperature, and the mean maximum temperatures of those months. ${ }^{19}$ In May, this hottest zone expands in area and extends into the plains of Pakistan, while Madurai and Dhaka remain in somewhat cooler areas.

Newspapers in June 2003 recorded that temperatures in Hyderabad, south-west of Raipur in the same temperature zone, had been $45^{\circ} \mathrm{C}$ for several days and 400 people had died from heatstroke. Elsewhere in India, it had been $49^{\circ} \mathrm{C}$ in the pre-monsoon period. How many times can the lens sustain being raised to these temperatures, approaching these figures without suffering permanent damage? The rate of direct chemical reactions, such as carbamylation or glycation, doubles with a $10^{\circ} \mathrm{C}$ rise in temperature, while the rate of enzymic reactions increases by a factor of 10 with a $10^{\circ} \mathrm{C}$ temperature rise.

Reports of the rise in temperature of the lens when animals were placed in sunlight, ${ }^{20}$ simulating what might happen in human eyes exposed to sunlight, have been overlooked. Temperatures were recorded with 24-guage thermistor needle probes inserted into the posterior chamber and the anterior lens cortex of 12 
rabbits and one monkey. Body temperatures were recorded by rectal probes. In New Haven, CT, lens temperature rose from 37.5 to $41^{\circ} \mathrm{C}$, a rise of $3.5^{\circ} \mathrm{C}$, when a rabbit was placed in the sun at $40^{\circ} \mathrm{C}$ for $8 \mathrm{~min}$. After a period in the shade, the probes were transferred to the second eye, the baseline starting temperature was higher, and after a further $9 \mathrm{~min}$ the lens cortex went to $41.5^{\circ} \mathrm{C}$. After $13 \mathrm{~min}$ in the sun at nearly $49^{\circ} \mathrm{C}$ in India, the lens temperature of the second eye of the monkey rose to $43^{\circ} \mathrm{C}$. A $1 \%$ transmission, Kodak filter introduced in front of the eye allowed the posterior chamber temperature to drop by $2^{\circ} \mathrm{C}$. Further experiments confirmed that the rapid increase in posterior chamber and lens temperatures in the sun were due to direct solar radiation through the cornea rather than the indirect effect of raised core body temperature.

So much attention has been given to the possible effects of ultraviolet radiation on the lens to explain the association of cataract with sunlight that we may have overlooked a more significant effect of temperature increases, either alone or in combination with other insults. This may become of even greater importance under conditions of global warming.

\section{Ultra violet radiation}

The second aspect of the physical environment which is of current concern is the potential increase in the solar ultraviolet radiation (UVR) reaching the earth's surface, due to thinning of the ozone layer of the atmosphere.

As solar UVR passes through the atmosphere, it undergoes scattering and absorption. Absorption is mainly by molecular oxygen and by ozone. In all, $90 \%$ of the ozone is in the stratosphere (up to $40 \mathrm{~km}$ ), the remainder is in the troposphere (Figure 5). These ozone layers prevent almost all of the short wavelengths less than $290 \mathrm{~nm}$ (which includes all of the UVC, $100-280 \mathrm{~nm}$ ) from reaching the earth's surface. They also absorb 70$90 \%$ of the UVB $(280-315 \mathrm{~nm})$.

The notorious 'ozone hole' over the Antarctic, discovered in the early 1980s by Farman of the British Antarctic Survey, ${ }^{21}$ has been deepening and widening at a frightening rate. Figure 6 shows the ozone map for 12th September 2002. The total ozone, in Dobson Units, hits the bottom of the scale over the South Pole. This phenomenon is the result of the release of man-made halocarbons, used in refrigeration, solvents, and other industrial uses, often thousands of miles away. Chlorine is generated from the halocarbons on the surface of small stratospheric cloud particles which can only form in the intense cold of the southern polar winter. As sunlight returns to the stratosphere during the Austral spring, the chlorine then catalyses the ozone destruction.

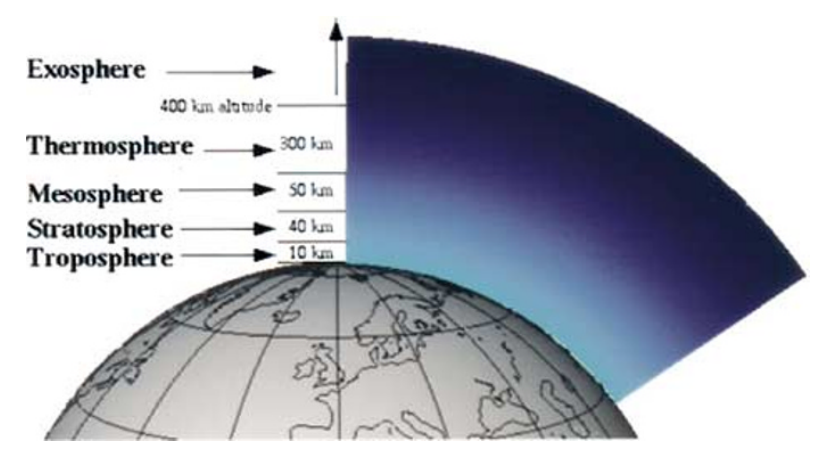

Figure 5 Layers of the atmosphere. Total ozone (DU) / Ozone total (UD), 2002/09/12

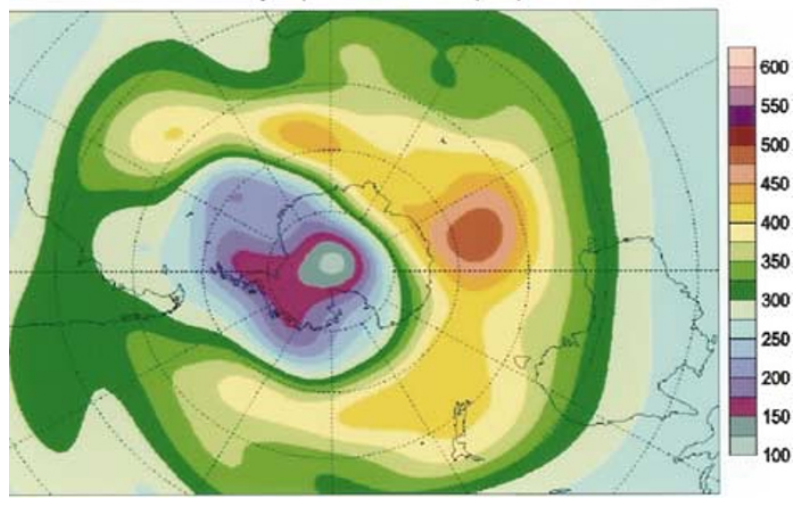

Figure 6 Ozone hole over Antarctica on 12 September 2002.

The latest report from the United Nations Environmental Programme/World Meteorological Organization is, however, cautiously optimistic. ${ }^{22}$ Following the Montreal Protocol and subsequent international agreements, chlorine levels may have passed their peak. The ozone 'hole' should start to reverse soon, and close off in about 60 years, provided countries adhere to their commitments.

Ozone loss has also occurred to a lesser degree in midlatitudes where most people live. At Chilton in Oxfordshire, the National Radiation Protection Board has recorded a trend of slow increase in ambient UV flux over the past 14 years. ${ }^{23}$ It is thought that the levels should soon start to reverse at these latitudes also.

\section{Possible ocular effects of UVR}

When UV reaches the eye, the proportion absorbed by different structures depends on the wavelength ${ }^{24,25}$ (Figure 7). The shorter wavelengths are the most biologically active. These are mostly absorbed at the cornea, for example, $92 \%$ at $300 \mathrm{~nm}$. The longer the wavelength, the higher the proportion that passes through the cornea to reach the lens, so that, at $360 \mathrm{~nm}$, in the UVA, over $50 \%$ is absorbed by the lens. 


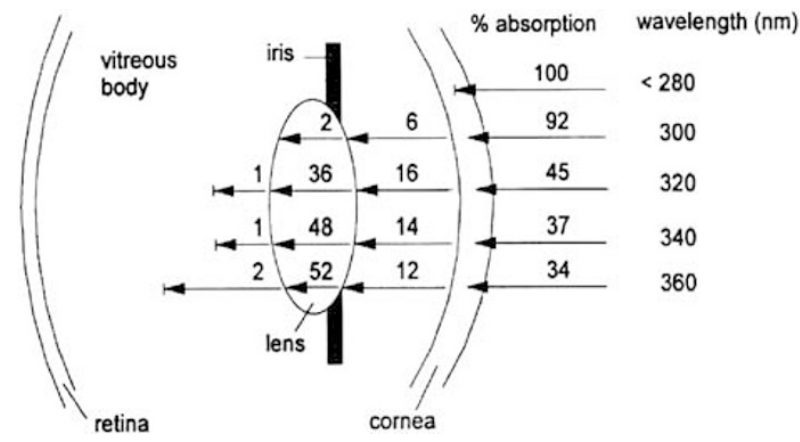

Figure 7 Absorption of different wavelengths of ultraviolet radiation by the structures of the eye.

Table 1 Ultraviolet radiation: possible ocular causal associations

\begin{tabular}{ll}
\hline & Strength of evidence \\
\hline External: & \\
Photokeratitis ('snow blindness') & Sufficient \\
Climatic droplet keratopathy & Limited \\
Pterygium & Limited \\
Pinguecula & Insufficient \\
Hyperkeratosis, carcinoma in situ, & Insufficient \\
carcinoma of conjunctiva & \\
& \\
Lens: & \\
Cataract & \\
Exfoliation & Limited \\
Anterior lens capsule changes & No evidence \\
& Limited \\
Choroid and retina: & \\
Uveal melanoma & \\
ARMD & Insufficient \\
\hline
\end{tabular}

The evidence for the health effects of UVR on the skin, immune system, and the eye has recently been updated in a report to the National Radiological Protection Board in the UK. ${ }^{26}$ Earlier consultations in Geneva aimed to assess the strength of the evidence for a causal association in each case. ${ }^{27}$ The ocular conditions for which UVR has been suggested to be a causative agent are listed in Table 1.

The biologically active shortest wavelengths are absorbed by the cornea, so that it is in the superficial cornea that we should expect to see the greatest effects of UVB. For example, there is good experimental evidence in rabbits and primates that the action spectrum for acute photokeratitis peaks in the UVB wavelengths. ${ }^{28}$ Clinically, snow blindness occurs under conditions of intense reflection of solar UVR from snow and ice.

It is likely that climatic droplet keratopathy, pterygium, cataract, and the lens capsule changes to be described below are caused, at least in part, by UVR, but stronger evidence is needed. The evidence for association with pinguecula, hyperkeratosis, carcinoma, uveal melanoma, and ARMD were considered insufficient. Exfoliation syndrome was not associated with UVR.

\section{Climatic droplet keratopathy (CDK)}

The current knowledge of CDK was reviewed in 1992, and there have not been significant advances since then. ${ }^{29}$ This chronic condition is characterized clinically by the deposition of translucent, grey material in the areas of the superficial corneas, which are exposed between the eyelids, looking under the slit-lamp like minute 'droplets'. In the youngest subjects, the deposits appear in narrow bands close to the limbus nasally and temporally, symmetrically in both eyes, and with time and continued exposure they encroach over the pupil to form a complete band (Figure 8). This interferes with vision, frequently reducing it to $6 / 24$ or less, and obscuring the details of the iris structure. As the accumulation of deposits becomes denser and heavier, loose fragments of superficial stroma appear to move around on the surface and then fall off (Figure 9).

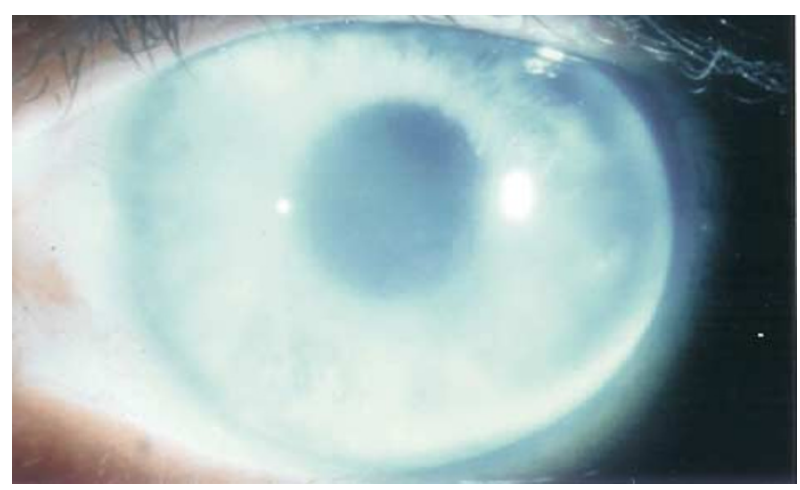

Figure 8 Climatic droplet keratopathy, moderately severe grade in Labrador.

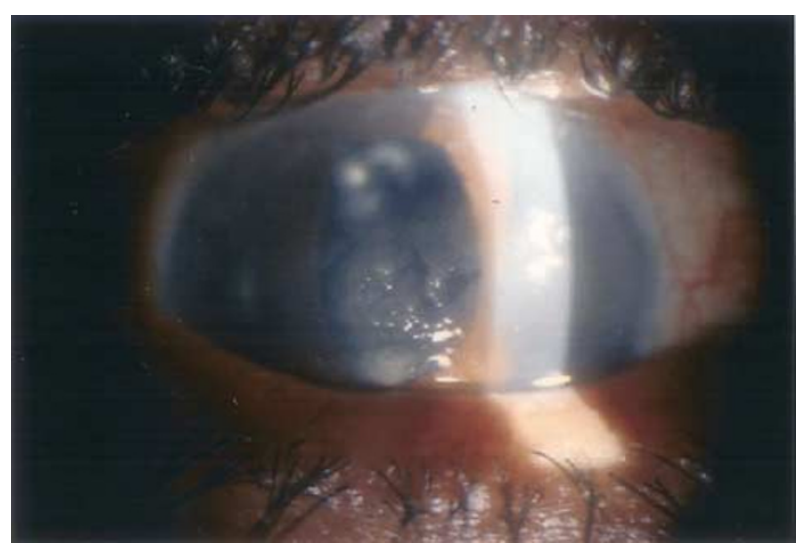

Figure 9 Advanced climatic droplet keratopathy, with fragments breaking off, in coastal area of Saudi Arabia. 


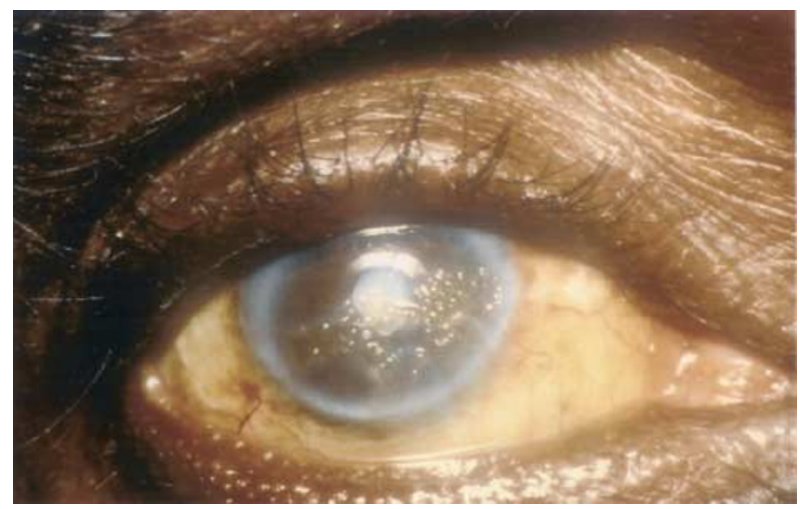

Figure 10 Advanced climatic droplet keratopathy, with raised yellow-brown nodules, in Somalia.

Sometimes you can ease them off with a spatula, leaving clearer stroma exposed. In the most advanced stages, raised nodules develop, yellow or brown in colour (Figure 10).

The distribution is confined to people who spend a large part of their lives outdoors. The earliest stages have occasionally been noted in farmers and gardeners in England, and more frequently in fishermen in Chesapeake Bay. The advanced stages invariably occur under environmental circumstances where there is opportunity for a high level of reflection of UVB from the ground surface. Thus, it has been recorded in Labrador, elsewhere in northern Canada, and in central Asia where UVB is reflected from snow and ice, from the Red Sea islands and coasts including Dahlak Islands, Saudi Arabia and Somalia, where UVB is reflected from white salt-impregnated coral sand, in salt-pan workers in southern India (Srinivasan M, personal communication), and certain desert areas in tropical or subtropical latitudes.

Light microscopy of specimens from Labrador showed discrete spheroidal bodies deposited in Bowman's layer and the superficial stroma of the cornea, distinct from the surrounding collagen. ${ }^{30}$ They stained in a complex way with a variety of protein stains, quite differently from the collagen and not characteristically of one particular type of protein. Electron microscopy showed the spheroidal material as very electron-dense and homogenous bodies $^{31}$ (Figure 11). There is no sign of transition from collagen.

Around the margins of the deposits, and in the area of the stroma where they occur, there was positive staining with fluorescent antibodies to different plasma proteins such as IgG, IgA, albumin, and fibrinogen, but not IgM. ${ }^{30}$ These findings were interpreted as suggesting that plasma proteins, which are known to be normally diffusing through the front part of the cornea from the limbus, are acted upon by the shorter wavelengths of

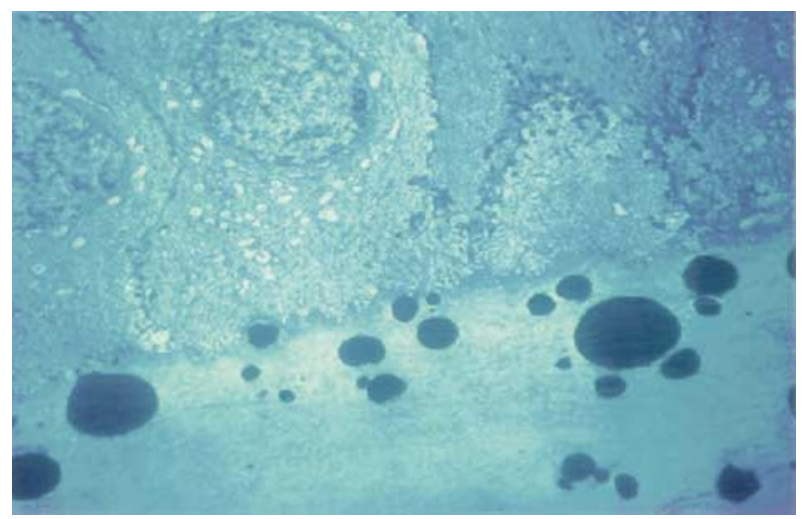

Figure 11 Electron microscopy of Bowman's layer and superficial stroma of cornea in climatic droplet keratopathy.

UVB penetrating into the superficial cornea, and are denatured to gradually accumulate in this location.

Everyone who has studied CDK has been persuaded that it is environmental in origin, because of the consistent histories of personal exposure to outdoor elements and because of the clinical distribution confined to the exposed part of the cornea. There is no evidence for genetic predisposition, or dietary influence. To summarize a large amount of epidemiological data and analysis, the prevalence, severity, and age of onset of CDK were documented in both clinic populations and selected total communities along the length of the East Coast of Canada from $50^{\circ}$ latitude north to $73^{\circ}$. There was a peak of both prevalence and severity around $55-56^{\circ}$ latitude, becoming less both North and South. ${ }^{32}$

This distribution was then compared and correlated with all the possible suggested climatic or physical agents such as temperature, humidity etc, which could be causing CDK. The one that fitted by far the best, with a good correlation coefficient, was the calculated total flux of UVB, which could be reflected upwards from snow and ice throughout the year. There is the possibility of some additional effect from wind-blown ice and snow particles causing inflammation of the conjunctiva.

The reason that the evidence for UV aetiology of CDK was considered insufficient in the WHO assessment is because much of it was based on ecological association, ${ }^{27}$ rather than measurement of individual subjects to UVR. If the UVB causation could be proved to the satisfaction of all workers in the field, CDK would be valuable as a biological marker of the cumulative dose of UVB received at the level of the eyes of an individual, for use in association studies of other possible effects in the eye.

In summary, CDK appears to be as close as we can get to a 'pure' environmental condition of the eye. The cornea is unpigmented and would be expected to be equally susceptible in all individuals to the effect of UVR, without the likelihood of any genetic predisposition. 


\section{Cataract}

Two points will be made about UV exposure and cataract. First, the association is with cortical cataract, while smoking is a risk factor for nuclear cataract. The Chesapeake Bay watermen study was the first to compare a detailed model of personal ocular UVB exposure with the presence and degree of cataract. ${ }^{33}$ It found an increased risk of cortical opacity, but not nuclear opacity, with increasing average annual ocular UVB exposure. Other studies in developed countries have now found a similar association with cortical cataract.

Second, the attributable risk estimates for UVB are being revised downwards. A recent report from the VIP study in Melbourne is instructive in this respect. McCarty and colleagues ${ }^{34}$ calculated attributable risk estimates for various factors for cataract, in order to prioritize medical and public health action. The attributable risk for cortical cataract of average ocular UVB exposure was $10 \%$. This means that - at least in Victoria - $10 \%$ of cortical cataract, equivalent to approximately $5 \%$ of all cataract, could be prevented if exposure to UVB was stopped completely. Combined with the knowledge that ozone depletion is now starting to reverse, this means that scare stories of a vast number of extra cases of cataract blindness due to UV were probably exaggerated.

\section{Anterior lens capsule changes}

There are changes in the anterior lens capsule which may also be attributed to exposure to UV. So far, these have only been reported from Somalia. ${ }^{35}$ There is, however, photographic evidence of similar changes in southern India, and there are anecdotal observations from one or two other locations where eyes are exposed to extreme climate conditions with very high reflected UV. The earliest change observed is a 'frosting' or whitish opacity at the level of the anterior lens capsule distinct from exfoliation, and confined to the area exposed by the pupil in its resting position. Increasingly severe changes appear to be a raised 'plateau' in the pupil zone (Figure 12a), then an anterior lenticonus, and finally a frank capsule 'bag' which herniates through the undilated pupil (Figures 12b and 13). These changes were invariably associated with $\mathrm{CDK}$, and inversely related to lens opacity. If $\mathrm{CDK}$ is taken as a marker for UVB exposure, UVB may also account for the capsule changes. It would be expected that the shortest wavelengths of UVB which penetrate the cornea would be absorbed at the anterior lens surface. This is a condition which would repay further study.

\section{Measurement of individual UVR exposure}

The estimates of lifetime exposures to UVB for epidemiological studies were based originally on measurements using mannequins, and then on

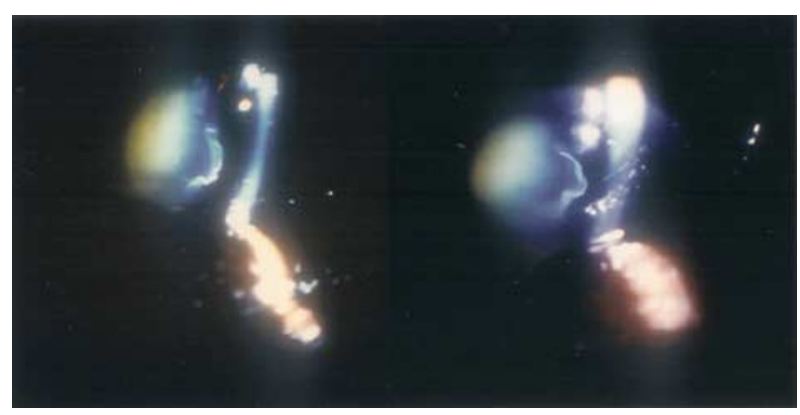

Figure 13 Anterior lens capsule changes, Somalia.

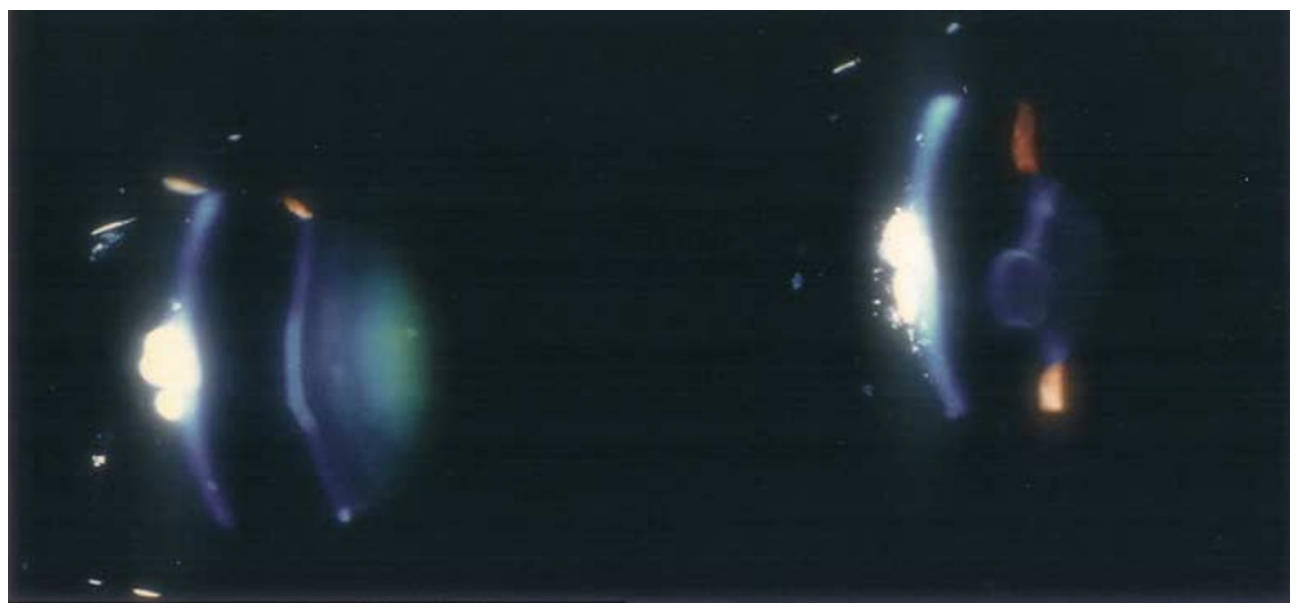

Figure 12 Anterior lens capsule changes, Somalia. 
questionnaires of time spent outdoors, use of spectacles, sunglasses, and hats, the effects of migration of the individual, and estimates of albedo of the ground surface (the albedo is the ratio of intensity of reflected light to what it receives from the sun). ${ }^{36}$. In all, $70 \%$ of the global UVR is received during the $4 \mathrm{~h}$ centred around local midday, when solar elevation is at its highest. Therefore, to simplify the calculations, some of the questionnaires are restricted to the central 4 or $6 \mathrm{~h}$ of the day. The months from mid-spring to mid-autumn, but not winter months, were included. ${ }^{37}$

In attempting to measure actual exposure at the eyes during normal daily activities, Lee and Diffey devised a headband with two miniature UV sensors, one just below the left eye, the other at the temporal side of the right eye (Figure 14). This device was worn by herdsmen going about their daily routine in Mongolia (as well as in other countries). Readings every second were downloaded into a data-logger worn on the belt (Figure 15). In this example, the top curve is the ambient UV from the sun (recorded by a biometer). The bottom two curves are the UV received by the sensors, integrated into the same units of Minimal Erythemal Dose/hour for each half hour. Contrary to what has been assumed in some cataract studies, in a number of individuals the highest cumulative readings were during the early morning hours when the sun was relatively low in the sky. There were reduced or absent readings during the middle of the day as the subjects rested or took shelter.

In Mongolia, it will also be important to obtain readings from individuals during the late winter or early spring when there is still much snow on the ground, and the sun is already high in the sky. The reflected UVR reaching the eyes is likely to be much higher than at other times of the year. Before further epidemiological studies of the association of UVR with ocular pathology are conducted, it is suggested that the estimates of individual exposure should be strengthened by calibration against actual measurements of individual exposure at different times of the day and in different seasons.

\section{The domestic environment}

Let us now turn to the 'domestic environment', a person's immediate hygienic and household

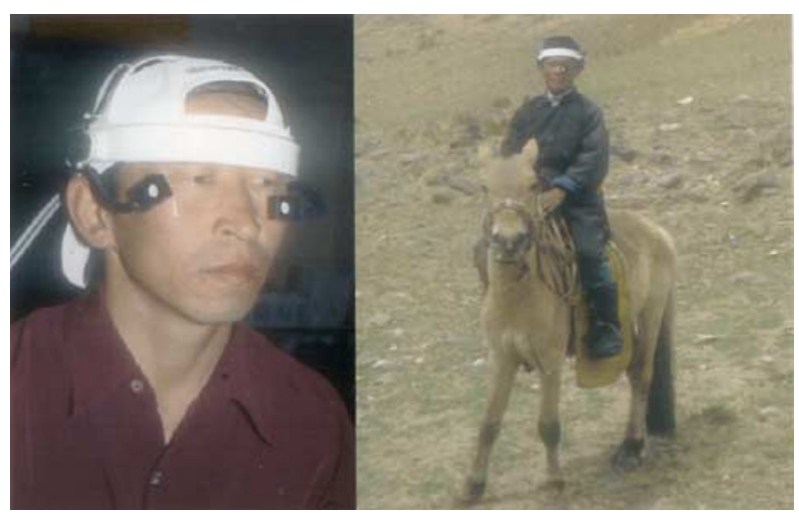

Figure 14 Miniature UV sensors worn on a headband throughout daily activities.

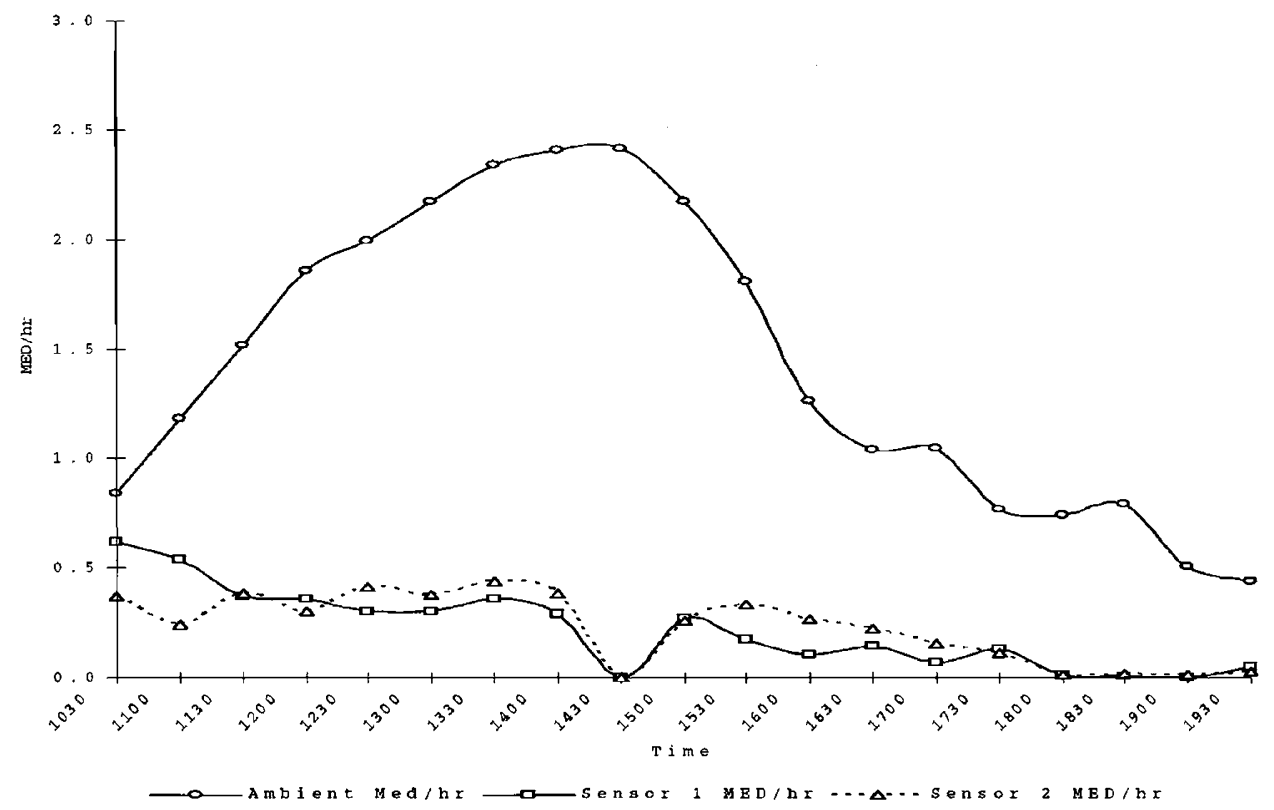

Figure 15 Day-time recordings of UVB by miniature sensors worn by a herdsman in Mongolia, compared with the ambient UV measured with a Robertson-Burger biometer. 


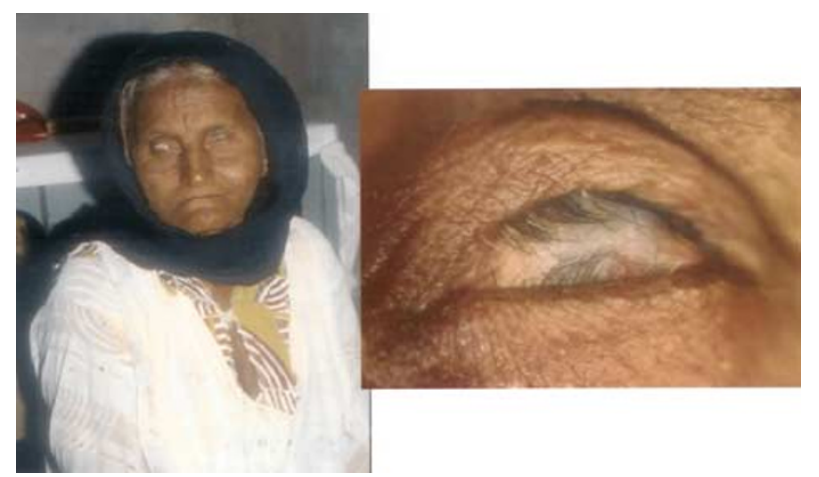

Figure 16 End-stage trachoma in North Yemen.

environment, which usually involves some human choice. Our example here will be trachoma.

Trachoma is a chronic infection of the conjunctiva caused by Chlamydia trachomatis, which is now classified as a bacterium. The initial episodes of infection are cleared, but repeated re-infection is thought to cause scarring of the conjunctival lining of the upper lid, entropion, trichiasis, corneal opacification, and ultimately blindness (Figure 16). The intense inflammatory stage has the highest infective load, as determined by quantitative PCR. The organism is thought to be spread from child to child, and child to adult, by fingers, cloths, and bed clothes, and - in many geographical regions - by eye-seeking flies.

\section{Genetic susceptibility}

There is considerable evidence for genetic variation in host susceptibility both to infection and in the risk of scarring and fibrosis. ${ }^{38,39}$

\section{Risk factors for blinding trachoma}

The risk factors include poverty, crowding, a preference for hot, dry, dusty areas, and lack of water. All these conditions apply in the Sahel of Africa, and in pockets in countries with less overall prevalence of trachoma such as the Rift Valley of Kenya, among the seminomadic Masaai. Other risk factors are a large fly population; inadequate latrines, proximity to cattle, which also results in many flies in the environment; and poor personal hygiene with dirty faces. In The Gambia the main eye-seeking fly is Musca sorbens, accounting for up to $90 \%$ of contacts with the faces of children (Figure 17). In all, $10 \%$ of the contacts are by the common house fly M. domestica.

There is evidence for each of these risk factors in different settings. For example, higher prevalence of active trachoma or greater severity is associated in several studies with distance from the water source. ${ }^{40}$

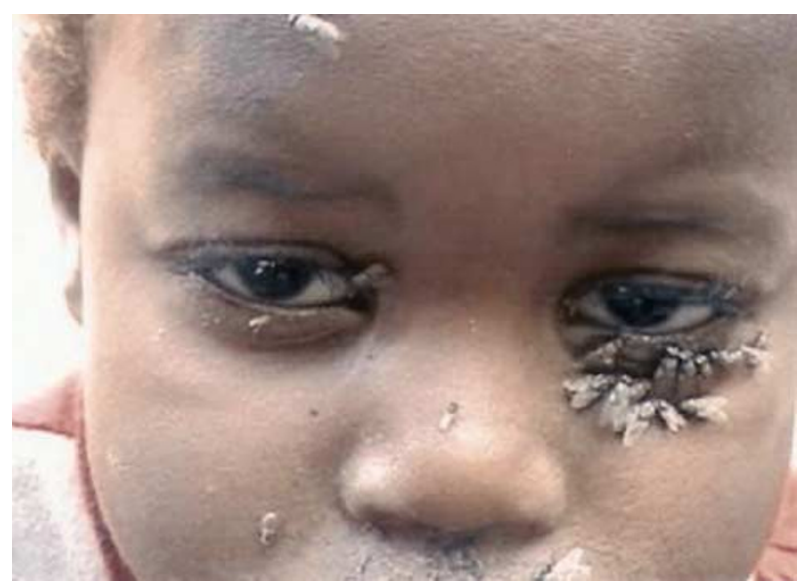

Figure 17 Flies (Musca sorbens) of different sizes on the face of a child infected with trachoma in The Gambia.

Behavioural factors surrounding the actual use of water for washing children is likely to be more important than the total amount of water available. ${ }^{41}$ The amount of water used for washing children is a factor. ${ }^{42}$ Children observed to have unclean faces, as opposed to clean faces, are at great risk $^{40}$ and the presence of nasal discharge plus flies on the face increases the risk. ${ }^{43}$

Face washing is likely to be effective not only by reducing direct spread of the organism on fingers and clothes, but also by interrupting the attraction of flies.

Active trachoma ${ }^{44,45}$ is related to absence of a latrine in the compound or household. Most recently, Burton et $a l^{46}$ have found an Odds Ratio of 12.9 (90\% CI 1.58-105) for high infective loads, measured by quantitative PCR, in households without a latrine. The importance of latrines seems to be because the best breeding medium for $\mathrm{Musca}$ sorbens is fresh human faeces. ${ }^{47}$ They cannot breed in the fluid consistency of material in a pit latrine, but require the material exposed on the ground.

\section{Behaviour and natural history of the flies}

Burton (personal communication) has taken video recordings in The Gambia of 250 children to study how these flies are behaving on the face. Some flies appear to come to inspect the secretions around the eyelashes or nose, and they fly off again. Others, mostly females, feed for a long time on the secretions around the eyelashes. It is thought that they require the extra protein before laying their eggs. The flies can be observed in detail, because the children are so used to them that they do not bother to brush them away. It can be seen that the sizes of the flies vary, some being obviously smaller (Figure 17).

Paul Emerson, an entomologist at the University of Durham, has studied the optimum breeding medium for these flies. ${ }^{47}$ The study was simple in concept, but difficult to conduct scientifically. In nine separate trials, 
Table 2 Breeding media for the trachoma vector Musca sorbens

\begin{tabular}{llc}
\hline Type of faeces & Positive trials & $\begin{array}{c}\text { Mean head width } \\
\text { of female flies }(\mathrm{mm})\end{array}$ \\
\hline Human & $6 / 9$ & 1.92 \\
Milk-fed calf & $3 / 9$ & 1.69 \\
Cow & $3 / 9$ & 1.59 \\
Dog & $2 / 9$ & 1.28 \\
Goat & $1 / 9$ & - \\
Horse & $0 / 9$ & - \\
Composting waste & $0 / 9$ & - \\
Soil control & $0 / 9$ & - \\
& & 1.86 \\
\hline
\end{tabular}

From Emerson et al $^{47}$.

in villages with active trachoma, buckets containing soil were set out. On each, a measured amount of faeces from different sources was placed - human, milk-fed calf, cow, dog, goat, horse - with controls of composting waste and plain soil (Table 2). All the flies hatching 2 weeks later were captured and analysed. Human faeces gave the most positives, but cow and calf were less frequent alternatives.

It seems that the sizes of adult flies, even of one species, depend on the quality of the medium for the larvae. Human faeces gave rise to flies with the widest mean head diameter $(1.92 \mathrm{~mm})$. Significantly, flies captured from the faces of children in the vicinity had almost the same head width on average $(1.86 \mathrm{~mm})$, indicating that they had almost all bred in human material.

\section{Intervention studies}

Can we use the information from these observational studies to test different types of practical intervention?

In Tanzania, West et $a l^{48}$ gave mass topical treatment with tetracycline to a number of villages. Half were then randomly assigned to a programme of face washing. A year later, children who kept their faces clean were half as likely to have trachoma, and a third as likely to have severe trachoma, as children who did not have clean faces.

Emerson has conducted a trial of fly control in The Gambia. ${ }^{49}$ Two pairs of villages were selected, one in the wet season and one in the dry season. One of each pair was sprayed for 3 months with an ultra-low-volume insecticide, deltamethrin, alternate days for 2 weeks, then twice weekly. After 3 months, there were $75 \%$ fewer $M$. sorbens and $71 \%$ fewer $M$. domestica in the intervention villages, and $75 \%$ fewer new cases of trachoma.

This trial showed that controlling flies, by itself, could make a difference. If would be too costly and not practical to carry out repeated spraying in a large
Table 3 Total population surveys Marakissa, The Gambia

\begin{tabular}{lccc}
\hline Age & \multicolumn{3}{c}{ Prevalence of active trachoma (\%) } \\
\cline { 2 - 4 } & 1959 & 1986 & 1996 \\
\hline $0-9$ & 65.7 & 4.0 & 2.4 \\
$10-19$ & 52.5 & 3.7 & 1.4 \\
$\geqslant 20$ & 36.7 & 1.0 & 0 \\
\hline
\end{tabular}

From Dolin et al..$^{50}$

number of villages in an infected region. Would installing latrines remove the flies equally well? We now need trials of latrine installation and use, and such trials are going on.

Marakissa is a village in The Gambia where we happen to have the results of three surveys of the total population over 37 years. ${ }^{50}$ Over that time, the prevalence of active trachoma has declined to almost zero in each age group (Table 3 ). The important feature of this village is that there has not been a targeted, longterm programme for the control of trachoma. Instead, a Methodist medical mission was established in the 1960s. The nurses encouraged good general hygiene washing, building latrines, keeping compounds swept, and moving the cattle out of the village. More recently, schools and a kindergarten have been established. The children are expected to be clean when they come to school.

The trachoma disappeared as a side benefit of general hygienic measures.

\section{Summary}

In trachoma, we have a disease where the essential causative agent is a bacterium; there appears to be some genetic variation in susceptibility; but the blinding consequences - and, indeed, the active infection - can be eventually eliminated by environmental measures and changes in behaviour.

\section{Cultural environment}

We come finally to the cultural and conceptual environment in which people live. This is again illustrated by the case of cataract - not, this time, by its aetiology, but by the barriers to surgical intervention.

Problems with patients attending for cataract surgery are almost universal in developing countries. Figure 18 shows the estimates of Cataract Surgical Rates (CSR), expressed as the number of operations per million population per year, collected by Allen Foster from different regions of the world. Australia and Japan lead the world at present. With a vigorous campaign, India is now operating on 3.5 million or more cataracts a year. 


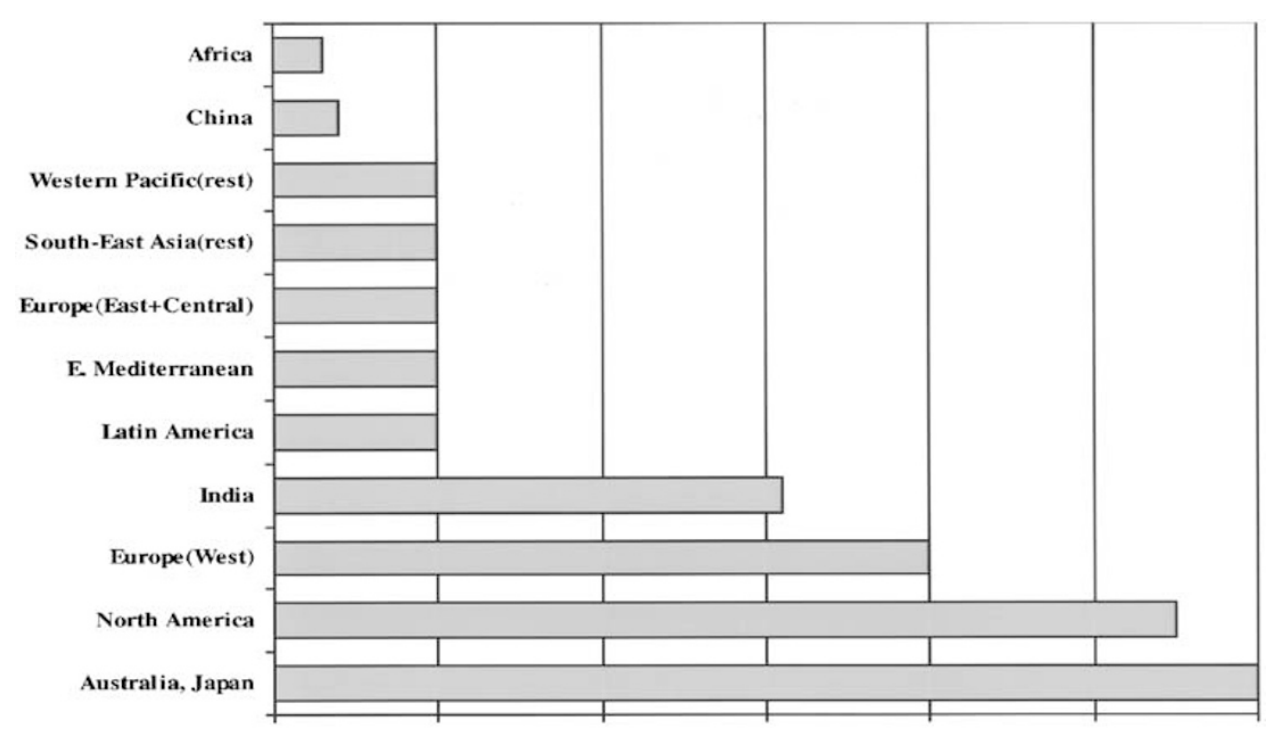

Figure 18 Estimates of cataract surgical rates in various regions of the world (operations / million population/year). Data collected by Allen Foster.

The CSRs in other developing countries are much lower. The lowest of all is sub-Saharan Africa. There are a number of reasons for these low levels - few cataract surgeons, widely dispersed populations - but also deep cultural factors of which we are only just beginning to be aware, let alone understand. A large literature on the perceived barriers is accumulating. Examples will be given from three countries.

\section{The Gambia}

Since 1986, The Gambia has had a programme for cataract surgery, set up by Dr Hannah Faal. When a second national survey was conducted as a follow-up in 1996, the rate of cataract blindness had fallen, but there were large numbers who had not taken advantage of this service. ${ }^{51}$ A second-year anthropology student, Joanna Johnson, spent a summer in The Gambia investigating the barriers in the unoperated patients, in two health districts, from the random sample. She applied the standard methods of qualitative research, including focus groups with a minimum of five adult relatives and neighbours of the patient, a semistructured questionnaire to the unoperated patients themselves, and a questionnaire administered to the different levels of eye

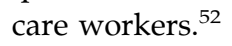

The results by the three methods were consistent. The declared barriers were: perceived cost; fear of the operation; lack of an escort; and lack of transport. Each of these has now been addressed by the National Eye Care Programme. But she also came to the conclusion that there were deep-seated cultural issues that would require much longer study by a medical anthropologist to begin to understand local attitudes to, for example, the ageing process, to vision and visual impairment, to beliefs about the causation of cataracts, and to the social status and role of the elderly.

\section{Bangladesh}

An extensive survey of blindness and visual impairment has recently been conducted in Bangladesh. ${ }^{53}$ Over 11600 subjects aged 30 years and older were examined in 154 urban and rural clusters throughout the country. The blindness rate in this age group was an astonishing $1.53 \%$. Cataract accounted for $80 \%$ of this, uncorrected aphakia for $6 \%$ and other refractive error for $1 \%$. This is a country with no trachoma and no onchocerciasis. Glaucoma prevalence seems to be particularly low, so that $87 \%$ of present blindness could potentially be corrected by cataract extraction and refraction.

It is true that in many areas in Bangladesh cataract services still need to be put in place. But, in Chittagong, there has been an Eye Infirmary setting high standards for many years. Dr M Osmani, while an MSc student in London, conducted an investigation in Chittagong as to why people had not come for cataract surgery. ${ }^{54}$ By standard methods, cost was the second cause, but the greatest problem was fear - fear of death; of the operation itself; of losing existing vision. The most revealing insights came when a female interviewer visited a female subject privately on her own. The female respondents feared:

- loss of privacy and dignity, especially using the toilet;

- that 'a male doctor will touch me'; 'how shall I let a male doctor operate on me?' (Muslims);

- loneliness; loss of control (widows); 
- rejection if they revealed their disability to husband and family;

- that vegetarian food might not be available (Hindus).

These are concerns which ophthalmologists in western environments would probably never have thought of.

\section{South Africa}

The last example is from KwaZulu-Natal, South Africa. Here, cost was not a problem because of the generous pensions to older people. A network of cataract surgeons has been set up in the district hospitals, so that there is one surgeon per 250000 people. Barriers of cost, access, and transport should have been overcome. Alan Rotchford conducted a detailed glaucoma survey in a random survey of over 1000 Zulus, aged 40 years and over in the Hlabisa District. Among them were 18 people blind $(<3 / 60)$ and six with severe visual impairment $(<6 / 60)$ in both eyes, as a result of operable cataract. They were given a detailed explanation by the ophthalmic nurse, and listed for surgery.

After 9-12 months, not one had attended for surgery! So Alan and his wife Karen, with a Zulu fieldworker Mr Mthewthwa, decided to visit them in their homes. In all, 20 were found, and consented to be interviewed. As expected, cost and transport did not feature in the replies. Table 4 gives examples of some of the responses.

Table 4 Examples of responses in KwaZulu-Natal

'...I won't go for an operation....I don't want any piece of my body to be buried while I am still alive...'

'... If I have to be operated, I'll just have to tell myself that that will be the end of me, and when I'm dead, people will talk about me. Maybe they will say I am dead because I went for an operation when I was old...'

'...I am afraid that I will be given a drug that will make me sleep forever...'

'...I would be happier with no vision so that someone would have to cook and clean for $\mathrm{me}^{\prime}$

From Rotchford et al..$^{55}$

The last comment is an important observation, revealing the expected status and privileges due to an elderly person.

We may be inclined to dismiss these views, in each country, as the fancies of ignorant people, but the reality is that these are the conceptual environments in which they live and function. What is the point of having a WHO target for the elimination of cataract blindness in South Africa, for example, if we do not take the time to understand this aspect of the environment?

The following sentences from John Simpson's book about the recent war in Afghanistan could apply equally to our work in trying to prevent and treat blindness: ${ }^{56}$

'...the modern world, I reflected, had come up against a barrier: not a technological one, but a barrier in human behaviour....

...The world's problems have less to do with what we can achieve, and more to do with what we want to achieve; in other words, our attitudes and opinions and feelings - our passions - remain, as ever, more influential than our intellect.'

\section{Conclusion}

This paper has attempted to give selected examples of ways in which the environment may influence the causation or the outcome of some eye diseases. With regard to causation, it is obviously important that we continue to identify genes contributing to multifactorial disorders (such as cataract, glaucoma, and ARMD), explore how they interact with environmental factors, and thereby understand the mechanisms at a cellular and biochemical level.

Following the sequencing of the human genome, how much impact will genomics actually have on healthcare, particularly in developing countries? This question was addressed by the WHO Advisory Committee on Health Research, Sir David Weatherall being the lead writer. ${ }^{57}$ The Committee warned that some of the claims for the medical benefits of genomics have undoubtedly been exaggerated, particularly with respect to the time scales required. Genomics has contributed to some progress in the diagnosis of communicable disease, and to understanding the mechanism of cancer, but it has so far contributed very little to the treatment of those conditions causing the main burden of disease in either sub-Saharan Africa or the Established Market Economies. The authors felt it was crucially important that a balance was maintained in research between genomics and more conventional and well-tried clinical research involving patients and epidemiological studies in the community.

With respect to eye disease, it is important that we learn more about the effect of temperature on the lens; the effects of ultraviolet radiation are of intrinsic interest; and genetic epidemiology should not be neglected. But, to make a difference to the rate of world blindness in our lifetimes, the most effective research will be directed to the domestic environment; into optimal strategies for eye health delivery in different settings; and into anthropological understanding of cultural environments.

Although these types of operational and qualitative research are unfamiliar to most ophthalmologists, it is 
essential that we understand and address the complete environment - physical, biological, domestic, and cultural - in which eye disease occurs.

\section{Acknowledgements}

I am indebted to my long-standing colleagues at the International Centre for Eye Health, Professor Allen Foster, Darwin Minassian, Clare Gilbert, Ian Murdoch and Richard Wormald for discussions of these issues over many years. Much of the data have been collected by Research Fellows at ICEH: Brendan Dineen, Astrid Leck, Richard Bowman, Alan Rotchford, Rupert Bourne, and Matthew Burton. Emma Cartwright and Pak Sang Lee assisted with the preparation of the lecture and this paper. I am grateful to Professor Jim Briden, Professor John Harding, Paul Emerson, Alastair McKinlay, and Angels Natividad-Sancho for giving time to answer questions on specific topics. The following kindly commented on the manuscript: Matthew Burton, Allen Foster, Ann Johnson, John Lee, and Robert Weale. Figure 1-3 are reproduced, with permission, from Lomborg B, The Skeptical Environmentalist, 2001, Cambridge University Press. Figures 8 and 10 are reprinted by permission of Oxford University Press from Oxford Textbook of Surgery, 2nd edn, by Morris PJ and Wood WC, 2000. Figure 14 is by courtesy of Pak Sang Lee, and Figure 17 courtesy of Matthew Burton.

\section{References}

1 Lomborg B. The Skeptical Environmentalist Measuring the Real State of the World. Cambridge University Press: Cambridge, UK, 2001.

2 Population Division, Department of Economic and Social Affairs, United Nations. World Population Prospects. The 2000 Revision. Highlights, Draft ESA/P/WP.165, 2001, (www.un.org/esa/population/unpop.htm.).

3 Congdon NG, Taylor HR. Age-related cataract. In: The Epidemiology of Eye Disease, Johnson GJ, Minassian DC, Weale RA, West SK (eds) Arnold: London, 2003, pp 105-119.

4 Minassian DC, Mehra V, Johnson GJ. Mortality and cataract: findings from a population-based longitudinal study. Bull World Health Organ 1992; 70: 219-223.

5 West SK, Muñoz B, Istre J, Rubin GS, Friedman SM, Fried LP et al. Mixed lens opacities and subsequent mortality. Arch Ophthalmol 2000; 118: 393-397.

6 Hennis A, Wu SY, Li X, Nemesure B, Leske MC. Lens opacities and mortality: the Barbados Eye Studies. Ophthalmology 2001; 108: 498-504.

7 Gilbert C, Rahi JS, Quinn GE. Visual impairment and blindness in children. In: The Epidemiology of Eye Disease, Johnson GJ, Minassian DC, Weale RA, West SK (eds) Arnold: London, 2003, p 264.

8 IPCC 2001, In: Watson RT and the Core Writing Team (eds). Climate Change 2001: Synthesis Report. A contribution of Working Groups I, II and III to the Third Assessment Report of the Intergovernmental Panel on Climate Change. Cambridge University Press: Cambridge, UK, 2001.

9 Mann ME, Bradley RS, Hughes MK. Global-scale temperature patterns and climate forcing over the past six centuries. Nature 1998; 392: 779-787.

10 McMichael AJ, Haines A, Slooff R, Korats S (eds) Climate Change and Human Health. World Health Organization: Geneva, 1996.

11 McMichael AJ. Population, environment, disease and survival: past patterns, uncertain futures. Lancet 2002; 359: 1145-1148.

12 Leck AK, Thomas PA, Hagan M, Kaliamurthy J, Ackuaku E, John $\mathrm{M}$ et al. Aetiology of suppurative corneal ulcers in Ghana and south India, and epidemiology of fungal keratitis. Br J Ophthalmol 2002; 86: 1211-1215.

13 Campbell CK, Johnson EM, Philpot CM, Warnock DW. Identification of Pathogenic Fungi. London Public Health Laboratory Service, 1996.

14 Minassian DC, Mehra V, Jones BR. Dehydrational crises from severe diarrhoea or heatstroke and risk of cataract. Lancet 1984; 1: 751-753.

15 Minassian DC, Mehra V, Verrey J-D. Dehydrational crises: a major risk factor in blinding cataract. Br J Ophthalmol 1989; 73: 100-105.

16 Harding JJ, Rixon KC. Carbamylation of lens proteins: a possible factor in cataractogenesis in some tropical countries. Exp Eye Res 1980; 31: 567-571.

17 Bhatnagar R, West KP Jr, Vitale S, Sommer A, Joshi S, Venkataswamy G. Risk of cataract and history of severe diarrhoeal disease in southern India. Arch Ophthalmol 1991; 109: 696-699.

18 Khan MU, Khan MR, Sheikh K. Dehydrating diarrhoea and cataract in rural Bangladesh. Ind J Med Res 1987; 85: 311-315.

19 Eliot J. Climatological Atlas of India. Indian Meteorological Department, Government of India: India, 1906.

20 Al-Ghadyan AA, Cotlier E. Rise in lens temperature on exposure to sunlight or high ambient temperature. $\mathrm{Br} J$ Ophthalmol 1986; 70: 421-426.

21 Farman JC, Gardiner BG, Shanklin JD. Large losses of total ozone in Antarctica reveal seasonal $\mathrm{ClO}_{x} / \mathrm{NO}_{x}$ interaction. Nature 1985; 315: 207-210.

22 Scientifica Assessment Panel of the Montreal Protocol on substances that deplete the ozone layer. Scientific Assessment of Ozone Depletion: 2002, UNEP/WMO 2002, (www.unep.ch/ozone/pdf/execsumm-sap2002.pdf. ).

23 Driscoll CMH, Campbell JI, Pearson AJ, Hunter N, Dean SF, Clark IE et al. Solar Radiation Measurements at the Network Six Sites in the UK, January - December 2002, NRPB - W37. National Radiological Protection Board: Chilton, Oxfordshire, OX11 0RQ, UK, 2003.

24 Boettner EA, Wolter JR. Transmission of the ocular media. Invest Ophthalmol 1962; 1: 776-783.

25 Sliney DH, Wolbarsht ML. Safety with Lasers and Other Optical Sources. A Comprehensive Handbook. Plenum Publishing Corp.: New York, 1980, pp 101-245.

26 Report of an Advisory Group on Non-Ionising Radiation. Health Effects from Ultraviolet Radiation, Documents of the NRPB, Vol 13 (1). National Radiological Protection Board: Chilton, Oxfordshire OX11 0RQ, UK, 2002.

27 World Health Organization. Environmental Health Criteria 160. Ultraviolet radiation. World Health Organization: Geneva, 1994.

28 Cogan DG, Kinsey VE. Action spectrum of keratitis produced by ultraviolet radiation. Arch Ophthalmol 1946; 35: 670-677. 
29 Gray RH, Johnson GJ, Freedman A. Climatic droplet keratopathy. Surv Ophthalmol 1992; 36: 241-253.

30 Johnson GJ, Overall M. Histology of spheroidal degeneration of the cornea in Labrador. $\mathrm{Br} J$ Ophthalmol 1978; 62: 53-61.

31 Johnson GJ, Ghosh M. Labrador keratopathy: clinical and pathological findings. Can J Ophthalmol 1975; 10: 119-135.

32 Johnson GJ. Aetiology of spheroidal degeneration of the cornea in Labrador. Br J Ophthalmol 1981; 65: 270-283.

33 Taylor HR, West SK, Rosenthal FS, Muñoz B, Newland HS, Abbey $\mathrm{H}$ et al. Effect of ultra-violet radiation on cataract formation. N Engl J Med 1988; 319: 1429-1433.

34 McCarty CA, Nanjan MB, Taylor HR. Attributable risk estimates for cataract to prioritize medical and public health action. Invest Ophthalmol Vis Sci 2000; 41: 3720-3725.

35 Johnson G, Minassian D, Franken S. Alterations of the anterior lens capsule associated with climatic keratopathy. Br J Ophthalmol 1989; 73: 229-234.

36 Rosenthal FS, Phoon C, Bakalian AE, Taylor HR. The ocular dose of ultraviolet radiation in outdoor workers. Invest Ophthalmol Vis Sci 1988; 29: 649-656.

37 Taylor HR, Munoz B, Rosenthal FS, West S. An abbreviated assessment of ocular exposure to ultraviolet radiation. Aust N Z J Ophthalmol 1992; 20: 219-223.

38 Mahdi OSM. Impact of host genetics on susceptibility to human Chlamydia trachomatis disease. Br J Biomed Sci 2002; 59: $128-132$.

39 Mozzato-Chamay N, Mahdi OSM, Jallow O, Mabey DCW, Bailey RL, Conway DJ. Polymorphisms in candidate genes and risk of scarring trachoma in a Chlamydia trachomatisendemic population. J Infect Dis 2000; 182: 1545-1548.

40 Taylor HR, West SK, Mmbaga BBO, Katala SJ, Turner V, Lynch $\mathrm{M}$ et al. Hygiene factors and increased risk of trachoma in central Tanzania. Arch Ophthalmol 1989; 107: 1821-1825.

41 West S, Lynch M, Turner V, Muñoz B, Rapoza P, Mmbaga $\mathrm{BBO}$ et al. Water availability and trachoma. Bull World Health Organ 1989; 67: 71-75.

42 Bailey R, Downes B, Downes R, Mabey D. Trachoma and water use: a case control study in a Gambian village. Trans Roy Soc Med Hyg 1991; 85: 824-828.

43 West SK, Congdon N, Katala S, Mele L. Facial cleanliness and risk of trachoma in families. Arch Ophthalmol 1991; 109: 855-857.

44 Tielsch JM, West KP Jr, Katz J, Keyvan-Larijani E, Tizazu T, Schwab L et al. The epidemiology of trachoma in Southern Malawi. Am J Trop Med Hyg 1988; 38: 393-399.
45 Courtright P, Sheppard J, Lane S, Sadek A, Schachter J, Dawson CR. Latrine ownership as a protective factor in inflammatory trachoma in Egypt. Br J Ophthalmol 1991; 75: 322-325.

46 Burton MJ, Holland MJ, Faal N, Aryee EAN, Alexander $\mathrm{NDE}, \mathrm{Bah} \mathrm{M}$ et al. Which members of a community need antibiotics to control trachoma? Conjunctival Chlamydia trachomatis infection load in trachoma endemic Gambian villages. Invest Ophthalmol Vis Sci 2003; 44: 4215-4222.

47 Emerson PM, Bailey RL, Walraven GE, Lindsay SW. Human and other faeces as breeding media of the trachoma vector Musca sorbens. Med Vet Entomol 2001; 15: 314-320.

48 West S, Muñoz B, Lynch M, Kayongoya A, Chilangwa Z, Mmbaga $\mathrm{BBO}$ et al. Impact of face-washing on trachoma in Kongwa, Tanzania. Lancet 1995; 345: 155-158.

49 Emerson PM, Lindsay SW, Walraven GEL, Faal H, Bøgh C, Lowe $\mathrm{K}$ et al. Effect of fly control on trachoma and diarrhoea. Lancet 1999; 353: 1401-1403.

50 Dolin PJ, Faal H, Johnson GJ, Minassian D, Sowa S, Day S et al. Reduction of trachoma in a sub-Saharan village in absence of a disease control programme. Lancet 1997; 349: 1511-1512.

51 Faal H, Minassian DC, Dolin PJ, Mohamed AA, Ajewole J, Johnson GJ. Evaluation of a national eye care programme: re-survey after 10 years. Br J Ophthalmol 2000; 84: 948-951.

52 Johnson JG, Goode V, Faal H. Barriers to the uptake of cataract surgery. Trop Doctor 1998; 28: 218-220.

53 Dineen BP, Bourne RRA, Ali SM, Noorul Huq DM, Johnson GJ. Prevalence and causes of blindness and visual impairment in Bangladeshi adults: results of the National Blindness and Low Vision Survey of Bangladesh. $\mathrm{Br} J$ Ophthalmol 2003; 87: 820-828.

54 Osmani MM. A qualitative research to identify the barriers to the uptake of cataract surgery in Chittagong District of Bangladesh. niversity of London, MSc Thesis, 2000.

55 Simpson J. News From No Man's Land. In: Reporting the World. Macmillan, 2002.

56 World Health Organization. Advisory Committee on Health Research. Genomics and world health: report of the Advisory Committee on Health Research. World Health Organization: Geneva, 2002.

57 Rotchford AP, Rotchford KM, Mthethwa, Johnson GJ. Reasons for poor cataract surgery uptake - a qualitative study in rural South Africa. Trop Med Int Health 2002; 7: 288-292. 